\title{
Políticas públicas e políticas linguísticas no Brasil: diretrizes para o Ensino Médio
}

\author{
Elisandra Filetti* \\ Izac Vieira**
}

\begin{abstract}
Resumo
O presente artigo discute o papel do planejamento de políticas públicas e linguísticas voltadas ao Ensino Médio (EM), o nível intermediário de acesso ao Ensino Superior, com o objetivo de discutir como as políticas linguísticas previstas em documentos oficiais, como a Lei de Diretrizes e Bases da Educação (LDB), os Parâmetros Curriculares Nacionais (PCN), entre outros, têm sido incorporados aos projetos curriculares das escolas públicas brasileiras e que reflexos essa incorporação trouxe para os resultados dos alunos nos sistemas de avaliação de grande escala.
\end{abstract}

Palavras-chave: políticas linguísticas, políticas públicas, avaliação em grande escala.

Public policies and language policies in Brazil: guidelines for secondary education

\begin{abstract}
This article discusses the role of public and language policy planning for Secondary Education as an intermediate level of access to higher education. It proposes to discuss how the language policies set out in official documents such as the Laws and Basic Guidelines for National Education (LDB), the National Curriculum Parameters (NCP), and others, have been incorporated into the curriculum projects of Brazilian public schools and how this incorporation has influenced student results in large-scale assessment systems.
\end{abstract}

Keywords: language policies, public policies, large-scale assessment.

\section{Introduçáo}

A implantação de políticas públicas da Educação, no Brasil, tem se tornado mais evidente nos últimos dez anos. Os novos direcionamentos governamentais têm alterado a dinâmica dos investimentos econômicos voltados para as políticas educativas, especialmente, àquelas que se detêm

* Professora Assistente II do Centro de Ensino e Pesquisa Aplicada à Educação/UFG; doutoranda em Letras e Linguística pela Universidade Federal de Goiás. E-mail: elisandra.filetti@yahoo.com.br

** Professor da Rede Estadual de Educação do Estado de Goiás; mestrando em Letras e Linguística pela Universidade Federal de Goiás. E-mail: hizac.vieira@yahoo.com.br 
na Educação Básica. Dados do Instituto Nacional de Pesquisas Educacionais Anísio Teixeira (INEP) divulgam que o investimento em Educação, em 2011, atingiu os 5\%; 1\% a mais do que no ano anterior. Essa tomada de decisão surge motivada pelos interesses brasileiros em tornar o país mais bem colocado socioeconomicamente diante de países desenvolvidos que pertencem à Organização para a Cooperação e Desenvolvimento Econômico (OCDE). A busca por desempenhos mais satisfatórios no campo da educação, especialmente quanto aos índices de leitura e escrita, tem levado o poder público a se preocupar com os índices de aproveitamento dos alunos brasileiros em relação à avaliação do nível educacional no país. Nesse sentido, políticas de planejamento educacional e, sobretudo, planejamento linguístico, tornaram-se objeto de interesse das instâncias governamentais, sobretudo, no que se refere à Educação Básica.

Um processo de debate complexo acerca dos rumos da educação brasileira se intensificou desde a década de 1980, a partir dos índices educacionais negativos obtidos sistematicamente e representados por problemas como repetência e evasão escolar. Muitos trabalhos e pesquisas foram realizados ao longo de quase trinta anos, buscando entender os elementos motivadores da pouca eficácia da escola brasileira. Problemas como acesso a dados oriundos de pesquisas em larga escala, relativos ao rendimento das escolas e de seus estudantes, constituíram barreiras para que se pudesse saber a real situação enfrentada pelo sistema educacional brasileiro.

Os órgãos governamentais, como o Ministério da Educação (MEC), se mobilizaram a fim de intervir nessa situação, por meio de uma postura mediadora entre os órgãos estaduais e municipais de educação, promovendo uma discussão acerca dos rumos legislativos, do emprego equânime das verbas anuais disponíveis, bem como criar espaços para fóruns de discussão, com uma maior participação da sociedade. Lamentavelmente, nem sempre esses fóruns têm uma ampla divulgação de suas pautas, tampouco a população entende que uma mobilização nessas instâncias é necessária para se defender os direitos de todos. De maneira lenta, o processo se estabelece e passa a ser objeto de interesse de outras parcelas da sociedade, inclusive da mídia.

A compreensão geral de que o problema do ensino no país se centralizava, sobretudo, nos níveis elementares da educação, levou instâncias governamentais, as próprias escolas e as universidades brasileiras a tentarem encontrar uma saída relacionada à melhoria da educação no Brasil. Como a educação é constituída por diversas esferas, verificou-se que a incidência do 
problema do letramento no Brasil estava localizado, entre outros fatores, na ineficiência da leitura e da escrita de alunos do Ensino Fundamental e do Médio. Tratava-se, claro, de um sério problema originado pela ausência de políticas linguísticas, públicas, que se detivessem em questôes de ensino e aprendizagem da língua materna.

A discussáo aqui empreendida centra-se justamente na relação entre as propostas de políticas linguísticas, promovidas pelo Ministério da Educação, e a incorporação ou não dessas diretrizes pelas escolas, bem como de uma discussão acerca da revisão dos currículos escolares. A necessidade de se estabelecer planos de qualificação de professores, discussão de métodos de ensino e avaliação, de abordagem da língua portuguesa, em suas mais diversas variantes, sobretudo, a língua padrão, tornou-se o cerne dos trabalhos e das pesquisas empreendidos a partir da apresentação dos Parâmetros Curriculares Nacionais (MEC, 2010).

Os PCN que visam a garantir a todos os jovens e a todas as crianças brasileiras o direito de usufruir de conhecimentos relevantes para a sua atuação como cidadãos no mundo são diretrizes estabelecidas para orientar o trabalho do professor no que se refere ao planejamento de aulas e ao aprimoramento do currículo escolar, em todo o território nacional. Evidentemente, o surgimento dos PCN também originou um debate a respeito da Lei de Diretrizes e Bases da Educaçấo Nacional (LDB) e da pertinência de vários artigos acerca da educação básica. Além desses documentos, em 2008, foram lançadas as Orientaçóes Curriculares para o Ensino Médio (OCEM), cujo propósito é garantir aos jovens do Ensino Médio um currículo fundamentado em uma base comum e em uma parte diversificada - a cargo das escolas - que, conjuntamente, devem ser orientadas por práticas interdisciplinares.

As Orientaçóes Curriculares atestam o caráter político do novo enfoque, visto que, "além disso, a política curricular deve ser entendida como expressáo de uma política cultural, na medida em que seleciona conteúdos e práticas de uma dada cultura para serem trabalhados no interior da instituição escolar" (BRASIL, 2008, p. 8).

Os PCN e as Orientaçóes Curriculares apenas póem em prática o que está previsto na LDB:

Art. $2^{\circ}$ - A educação, dever da família e do Estado, inspirada nos princípios de liberdade e nos ideais de solidariedade humana, tem por 
146 Polyphonía, v. 23/1, jan./jul. 2012

finalidade o pleno desenvolvimento do educando, seu preparo para o exercício da cidadania e sua qualificaçáo para o trabalho.

Art. $3^{0}$ - $\mathrm{O}$ ensino será ministrado com base nos seguintes princípios: I - igualdade de condiçóes para o acesso e permanência na escola; II - liberdade de aprender, ensinar, pesquisar e divulgar a cultura, o pensamento, a arte e o saber.

As condiçôes de acesso ao desenvolvimento pleno do cidadáo, em condiçôes de igualdade, bem como o acesso às manifestaçóes culturais são retomadas nos demais documentos propostos pelo Governo Federal, embora a realidade aponte sérias dificuldades de implantação de uma proposta educacional que requisite do aluno, do professor, da escola e da comunidade tantas habilidades e condiçóes prévias que permitam o acesso pleno dos alunos ao bem cultural.

Quanto às questôes linguístico-pedagógicas, a proposta de caráter humanista presente nos documentos governamentais é extremamente pertinente, contextualizada e atual. No entanto, as condiçóes de aplicação dessa proposta, em muitas escolas e regióes, sáo inviabilizadas pela falta de formação adequada e continuada de professores, pelas instalaçóes físicas inadequadas e pela ausência de bibliotecas, por exemplo.

Para Gatti (2009, p. 12),

a contundência dos dados obtidos até aqui (pesquisa realizada pela autora) leva o Ministério da Educaçấo e alguns dos Estados da federação a desenvolver uma política de avaliação de redes de ensino de forma a trazer a público os resultados, na intenção de se buscar formas de superaçáo da precária situação das aprendizagens escolares. Os resultados médios eram muito preocupantes. Estímulos vindos de órgãos internacionais tiveram papel relevante na consolidação e ampliação dessas avaliaçôes.

A partir dessas consideraçóes iniciais, o presente artigo direciona a discussão para os propósitos linguísticos que subsidiam as políticas de ensino de Língua Portuguesa no Brasil, a partir dos anos 1990, assim como o entendimento do papel do Ensino Médio como nível de acesso à formação superior dos estudantes brasileiros. 


\section{Políticas linguísticas para o ensino de língua materna no Brasil: o ensino de Língua Portuguesa no Brasil e os processos de avaliaçáo em larga escala}

Com a implantação das diretrizes previstas nos Parâmetros Curriculares Nacionais, o ensino de língua materna tem se afastado, aos poucos, da visão tradicionalista de ensino de língua, calcada numa concepção behaviorista de aquisição da linguagem, assumindo outra, de caráter interacionista, contextualizado (BAKTIN, 1997).

No Brasil, até a década de 1980, o ensino da língua materna esteve regido por práticas de ensino de língua desvinculadas, em sua maioria, de uma proposta contextualizada, do uso da língua em suas diversas manifestaçóes (oral e escrita), especialmente, desvinculada da importância da leitura aliada à produção textual. $\mathrm{O}$ ensino centralizado em regras gramaticais da norma padrão, culta, sobressaía-se em detrimento de atividades de reflexão sobre o uso da língua em contextos específicos como o da literatura e de outros gêneros discursivos, dentre eles, o jornalístico, por exemplo. Essa prática da gramática pela gramática tem mudado.

Em princípio, a Linguística Textual, a Sociolinguística, enfim, as áreas da Linguística que concebem a língua como um sistema que envolve o papel dos falantes e sua intervençáo sobre a língua em uso contribuiu imensamente para se debater a função do ensino da língua materna nas escolas brasileiras. $\mathrm{O}$ processo ainda é lento, pois ainda é forte a tendência normativista nas escolas.

Com o advento dos PCN, as discussóes sobre os dados relativos ao desempenho de alunos brasileiros do Ensino Médio, em processos avaliativos de larga escala, nacionais ou náo, tais como o Programa Internacional de Avaliação dos Estudantes da Organização para a Cooperação e Desenvolvimento Econômico (PISA), o Exame Nacional do Ensino Médio (ENEM), e o Índice de Desenvolvimento da Educação Básica (IDEB) ganharam relevância. Todos esses sistemas de avaliação de larga escala visam ao levantamento das condiçôes de letramento dos alunos das mais diversas localidades no mundo.

Esses conjuntos de avaliação têm por objetivo aferir as condiçóes reais de aprendizado de alunos do EM acerca de disciplinas variadas, entre elas Língua Portuguesa ou outra língua materna - caso do PISA -, Matemática e Ciências, envolvendo questôes de leitura e interpretação de enunciados, 
cálculos etc. A avaliação do PISA, por exemplo, revelou que a educação brasileira apresentou um ligeiro crescimento, mas o Brasil ainda ocupa uma posição preocupante: em um ranking de 65 países, somos o $53^{\circ}$ colocado em Leitura e Ciências e $57^{\circ}$ em Matemática.

A média brasileira nessas disciplinas foi de 401 pontos, bem abaixo da pontuação dos países mais desenvolvidos, que obtiveram 496 pontos. Em leitura, o Brasil alcançou 412 pontos; em Matemática, 386 e em Ciências, 405. Em 2006, a pontuação foi de 393 em Leitura, 370 em Matemática e 390 em Ciências. Esse resultado nos deixa atrás do México, do Uruguai, da Jordânia, da Tailândia e de Trinidad e Tobago.

Os Quadros 1 e 2, abaixo, ilustram os índices de aproveitamento relativos às áreas avaliadas pelo PISA, bem como o índice de rendimento dos países latino-americanos com aproveitamento acima de 360 pontos, referente ao período intercalado dos anos de 2000-2009.

Quadro 1. Comparativo dos três últimos resultados do Brasil no PISA

\begin{tabular}{|l|r|r|r|r|}
\hline Etapas/Modalidades de Educação Básica & $\begin{array}{r}\text { PISA } \\
2000\end{array}$ & $\begin{array}{r}\text { PISA } \\
2003\end{array}$ & $\begin{array}{r}\text { PISA } \\
2006\end{array}$ & $\begin{array}{r}\text { PISA } \\
2009\end{array}$ \\
\hline Número de alunos participantes & 4.893 & 4.452 & 9.295 & 20.127 \\
\hline Leitura & 396 & 403 & 393 & 412 \\
\hline Matemática & 334 & 356 & 370 & 386 \\
\hline Ciências & 375 & 390 & 390 & 405 \\
\hline
\end{tabular}

Fonte: INEP

Quadro 2. Resultados de alguns países da América Latina no PISA - modalidade leitura

\begin{tabular}{l|c|c|c|c}
\hline Países da América Latina & 2009 & 2006 & 2003 & 2000 \\
\hline Argentina & 398 & 374 & - & 418 \\
\hline Brasil & 412 & 393 & 403 & 396 \\
\hline Colômbia & 413 & 385 & - & - \\
\hline Peru & 370 & - & - & 327 \\
\hline Uruguai & 426 & 413 & 434 & - \\
\hline
\end{tabular}

Fonte: INEP

No Brasil, o ENEM parece ser um dos processos avaliativos que mais atraem os olhares, uma vez que se propôs, a princípio, a avaliar as condiçóes 
do estudante do EM e tornou-se, atualmente, um instrumento de acesso de alunos à universidade, pois parte da nota obtida na avaliaçáo pode ser incorporada à do vestibular ou mesmo substituí-la, permitindo a inclusão do aluno de escola pública nas universidades brasileiras, especialmente, as públicas. É importante ressaltar que o ENEM surge num contexto em que as políticas públicas educacionais assumem o discurso da inclusão de alunos afrodescendentes, indígenas e, mais recentemente, os alunos de baixa renda mediante o sistema de cotas. Trata-se de um movimento do Governo Federal, diante das reivindicaçóes das classes e dos movimentos sociais, em tentar desfazer a desigualdade no Brasil e diminuir os problemas de formação do brasileiro.

Num contexto favorável às políticas de inclusão social, implementaramse também as políticas de inclusão de natureza sociolinguística, ao menos, como indicadoras de novas práticas discursivas nas escolas. A abertura que os PCN propunham ao se trabalhar a língua em uso, sob um ponto de vista interacional, a partir de uma infinidade de gêneros discursivos, além do cotejamento de variedades linguísticas, desencadeou um processo de alteração de posturas teórico-metodológicas nunca vistas antes no Brasil. É claro que, por trás dessa postura recomendada pelo MEC, há o olhar e o acompanhamento de linguistas e educadores conscientes da realidade linguística brasileira. Entretanto, somente definir princípios norteadores para o ensino de língua portuguesa no Brasil não é suficiente como expressam os dados do Quadro 3 com os resultados de algumas escolas públicas do Estado de Goiás, no Exame Nacional do Ensino Médio, em 2009. Elas são algumas das escolas públicas federais e estaduais mais representativas quanto à tradição escolar, localização na cidade e ao número de alunos.

Em algumas das escolas, o número de participantes do ENEM oscila um pouco, variando nesses dois últimos anos. Os índices de aproveitamento em Leitura, como demonstram os dados, atingem uma média de 6.0 (seis) pontos, média considerada razoável pelos avaliadores do ENEM, mas que não deixa de evidenciar um nível ainda incipiente de domínio de leitura. As metas do governo federal propóem um crescimento de mais de $50 \%$, conforme os dados do Índice de Desenvolvimento da Educação Brasileira (IDEB), relativos à Educação Básica nos próximos anos. Em relação à leitura e à escrita, açoóes envolvendo a compreensão da língua sob um aspecto mais amplo do funcionamento textual são imprescindíveis para que os alunos 
desenvolvam as competências e habilidades exigidas pelos PCN e pelos processos avaliativos em Língua Portuguesa.

Quadro 3. Resultado ENEM 2009 - Escolas Públicas do Estado de Goiás

\begin{tabular}{|l|c|c|c|c|c|}
\hline $\begin{array}{c}\text { Escolas Públicas } \\
\text { Participantes } \\
\text { em 2009 }\end{array}$ & $\begin{array}{c}\text { Tipo de } \\
\text { dependência }\end{array}$ & $\begin{array}{c}\text { Número } \\
\text { de alunos } \\
\text { matriculados }\end{array}$ & $\begin{array}{c}\text { Número de } \\
\text { participantes }\end{array}$ & $\begin{array}{c}\text { Média } \\
\text { da prova } \\
\text { objetiva }\end{array}$ & $\begin{array}{c}\text { Media final } \\
\text { (objetiva+redação) }\end{array}$ \\
\hline $\begin{array}{l}\text { Colégio Estadual } \\
\text { Pedro X. Teixeira }\end{array}$ & Estadual & 290 & 82 & 469.58 & 512.53 \\
\hline $\begin{array}{l}\text { Colégio Estadual } \\
\text { Pedro Gomes }\end{array}$ & Estadual & 286 & 107 & 484.17 & 431.69 \\
\hline $\begin{array}{l}\text { Colégio Estadual } \\
\text { Lyceu de Goiânia }\end{array}$ & Estadual & 230 & 99 & 509.28 & 534.24 \\
\hline $\begin{array}{l}\text { Colégio Militar } \\
\text { Hugo de } \\
\text { Carvalho Ramos }\end{array}$ & Estadual & 536 & 260 & 558.23 & 631.25 \\
\hline $\begin{array}{l}\text { Instituto Federal } \\
\text { de Educação } \\
\begin{array}{l}\text { Ciência e } \\
\text { Tecnologia } \\
\text { de Goiás }\end{array}\end{array}$ & Federal & 82 & 24 & 604.85 & 620.13 \\
\hline $\begin{array}{l}\text { Centro de } \\
\text { Ensino e Pesquisa } \\
\text { Aplicada } \\
\text { à Educação }\end{array}$ & Federal & 58 & 44 & 553.68 & 612.92 \\
\hline
\end{tabular}

Fonte: INEP

Concepção de língua nas diretrizes curriculares nacionais

O Brasil se constitui, em sua imensidáo territorial, por uma variedade de modalidades linguísticas, de gêneros tanto orais como escritos, que circulam pela sociedade e, sendo assim, a escola não pode deixar de discutir a diversidade sociocultural e linguística que envolve a língua portuguesa. A partir de tal constatação, surge a necessidade de se estabelecer avaliaçôes sobre a educação como um todo (sobre o desempenho de alunos, professores e do próprio sistema educacional), uma vez que a pressão externa e econômica se faz forte e contundente, em relação aos resultados esperados de um país, como o Brasil, que se mostra competitivo e que está em desenvolvimento. Porém, do ponto de vista teórico, o confronto entre uso e norma linguística tem sido árduo. 
A inserção da modalidade oral do Português do Brasil, como outro registro importante do estudo linguístico, pretende apresentar ao estudante a riqueza da língua materna, como ela se manifesta nas diversas situaçóes comunicativas e interacionais. Compreender que a língua é dinâmica, fluida, sujeita a alteraçóes permite ao falante ser consciente dos propósitos interacionais selecionados por ele e aos quais se submete também. Para Neves (2003, p. 85), “o tratamento da gramática num espaço escolar há de respeitar a natureza da linguagem, sempre ativada para a produçáo de sentidos, o que se opera nesse jogo entre restriçóes e escolhas equilibra o sistema" $[\ldots]$.

A concepçáo de língua subjacente aos processos avaliativos parece ser a da língua como um sistema gramatical cujos componentes estão em função das escolhas dos falantes, das necessidades de interação mediante a materialização do discurso em gêneros textuais, visto que o texto é a unidade relevante de análise da língua.

Os sistemas de avaliação da proficiência dos estudantes brasileiros, em relação a sua língua materna, procuram aferir em que medida esses estudantes desenvolveram, durante os anos de escola básica, sua competência linguística de leitura e escrita. Não se prioriza mais somente a capacidade de o aluno dominar as regras normativas da língua, mas sim sua capacidade de reflexão sobre fatos sociais, históricos, econômicos, entre outros, mediante a materialização textual, o que evidencia, assim, a sua formação como um todo.

Um olhar mais atento das instâncias educativas parece estar sendo direcionado como meta no Brasil. A assunção dessa responsabilidade, nas universidades, escolas e, especialmente, como prioridade política dos Governos, é o primeiro passo para a melhoria da Educação Básica neste país. Não basta que o poder público determine um rumo teórico-metodológico a ser seguido por professores e alunos. Aliados a essa orientação, o investimento econômico no processo de qualificação de professores, as condiçôes salariais e os materiais de trabalho são condiçôes elementares para que o ensino seja também de qualidade e laico.

A perspectiva de ensino de língua portuguesa, atualmente, passa por contrastes muito sérios. De um lado, a proposta de um ensino de língua inovador, de um Ensino Médio também inovador (MEC, 2009), segundo o qual a escola básica deve privilegiar a formação humanista do aluno, propondo a inclusão de disciplinas adequadas ao contexto sócio-histórico 
de cada regiāo, apresentando propostas de ensino interdisciplinares que deverão orientar essa formação plena do aluno e cidadão. De outro, uma escola ainda composta por professores com poucas chances de qualificação, que já estão trabalhando há bastante tempo ou que acabaram de sair das universidades e que, no entanto, estão distantes do acesso econômico à informação (jornais, filmes, gramáticas, dicionários etc.) e à formação continuada (qualificação, apresentação em congressos), enfim, a um bem cultural amplo e diversificado.

Investimentos têm sido feitos ou, pelo menos, direcionados às escolas, entretanto, não existem mecanismos eficazes de fiscalização que garantam que os recursos advindos do Fundo de Manutençáo e Desenvolvimento da Educação Básica e de Valorização dos Profissionais da Educação (FUNDEB) e Fundo de Manutenção e Desenvolvimento do Ensino Fundamental e de Valorização do Magistério (FUNDEF) sejam igualmente repassados a todas as escolas públicas e que todas tenham de cumprir um planejamento de melhoria das condiçôes gerais dessas escolas, como explica Lyra Silva (2006, p. 61):

A sociedade brasileira reconhece um valor político-social constitutivo da experiência de financiar a educação pública no país. Reconhece esse direito ao garantir a presença do mecanismo de vinculação da receita de impostos para a manutençáo e desenvolvimento do ensino (MDE) na lei. O poder público, por outro lado, tem descumprido, nos meandros de suas decisōes e atos, o objetivo de uma boa construção legislativa em recursos financeiros educacionais. A prática oficial desse financiamento, em vez de tratar de verbas públicas obrigatórias à educação, esforçase por verbas destinadas à educaçáo, termo que evoca mais a vontade política dos governantes, permanecendo como tal, mesmo depois da lei instituída.

Estabelece-se, assim, um círculo que dificilmente pode ser quebrado e as condiçóes de ensino e aprendizagem na escola básica continuam arcaicas, ineficazes e, sobretudo, recebem cobrança da sociedade como se a escola fosse a única dimensão responsável pela Educação no país.

Inserido nesse contexto, está o ensino de língua portuguesa, que deve conciliar o ensino da norma padrão aos demais usos dessa mesma língua, organizada em gêneros discursivos variados, de maneira que possibilite o bom desempenho dos alunos nas provas do ENEM, PISA e vestibulares, além de prepará-los para a vida. Trata-se de um trabalho hercúleo diante de tantas adversidades. 
Críticas surgem à escola porque a sociedade considera que "nossos alunos e filhos não sabem escrever bem, não sabem português". Ainda, por motivo de uma perspectiva tradicionalista de ensino de língua, fundamentada na ideia de que a língua-pátria é o padrão lusitano do século XIX, a ideia que paira na sociedade é de que os alunos não sabem gramática tradicional, portanto, não obtêm sucesso nos exames nacionais.

A questão não é tão simples assim. Se por um lado, o governo institui diretrizes voltadas ao ensino que defendem o uso linguístico e os gêneros discursivos que circulam socialmente, por outro lado, os avanços da Linguística ainda não são de todo conhecidos pelos cidadãos brasileiros. Isso evidencia o problema de leitura no Brasil. $\mathrm{O}$ raro acesso à leitura e, portanto, à escrita, não é uma questáo única da escola, é de toda a sociedade que ainda não lê adequadamente ou raramente tem acesso às situaçóes de leitura. Por isso, o problema acerca do letramento no Brasil ainda é táo sério - a ausência de leitura e escrita não se restringe a uma única camada da população, mas parece ser, numa certa medida, um problema de todos os cidadãos que não construíram o hábito cultural da leitura.

Neves (2010, p. 172) assim considera a situação de ensino e aprendizagem da língua materna no Brasil:

Nossos currículos, bem como nossa escola, refletem uma insensibilidade notável quanto à sua missão como órgão essencial de direcionamento da visão da língua e de linguagem na comunidade. $\mathrm{Na}$ escola, quando os alunos sáo postos a falar da língua que sustenta sua identidade na sociedade em que interagem - a nossa língua portuguesa -, eles teriam de ser levados a desprender-se de um tradicional discurso sobre a língua que a retira completamente do uso, para assim, poder mover-se sustentavelmente no mundo da linguagem.

Não somente a escola e seus alunos devem se inserir nesse "mundo linguístico sustentável”, mas a sociedade como um todo, e essa realidade só pode ser possível mediante políticas públicas e linguísticas. Segundo Lyra Silva (2006, p. 62-63), as políticas de financiamento da educação, subordinadas às políticas socioeconômicas, têm sido uma das mais alteradas legalmente. Durante os anos 1990, a aplicação dos recursos financeiros públicos para a educação consolidou o acúmulo de problemas advindos de décadas anteriores e estancou todo o processo de crescimento educacional no país. Os dados pouco animadores do desempenho de alunos brasileiros 
nos sistemas de avaliação citados neste artigo exemplificam o resultado da inapetência das políticas públicas para a educação no Brasil.

Bourdieu (2007, p. 131), ao analisar o sistema educacional francês, admite que a ação pedagógica assume funçóes da maior importância para a sociedade e ameniza o caráter da violência simbólica integrada a essas açóes. Para o autor,

o êxito escolar é função do capital cultural e da propensão a investir no mercado escolar (tal propensão dependendo das chances objetivas de êxito escolar) e, em consequências, as fraçôes mais ricas em capital cultural e mais dispostas a investir em trabalho e aplicação escolar são aquelas que recebem a consagração e o reconhecimento da escola.

Nesse sentido, compreende-se, segundo o autor, que o valor da escola é limitado à sua relativa autonomia para gerenciar a produção e a reprodução de ideias. O sistema escolar está sujeito às determinaçóes da política de capital e mesmo as reivindicaçóes acerca dos investimentos escolares para a "formação do homem" estão sujeitas ao "lucro econômico e simbólico" que o sistema social impóe. Assim, o gerenciamento das verbas governamentais, em sua origem, já nascem predeterminadas por uma ordem do lucro econômico, o que nem sempre garante o acesso de todos à educaçẫo com qualidade.

\section{O papel do Ensino Médio na sociedade brasileira}

Os programas de melhoria dos índices educacionais do Brasil estão sujeitos às condiçóes contextuais e atuais impostas pela ordem econômica mundial. Um dos alicerces fundamentais para tornar um país competitivo no cenário mundial é possuir uma base educacional consolidada, com sujeitos capazes de desempenhar suas funções intelectuais e tecnológicas de maneira confiável e instrumentalizada. Isso significa que o Estado deve ser responsável por criar condiçóes de ensino para que o futuro profissional desempenhe adequadamente o seu papel no mercado de trabalho.

O Exame Nacional do Ensino Médio (ENEM), em princípio, como já salientado, surgiu como uma ferramenta para medir o desempenho intelectual dos alunos do Ensino Médio brasileiro em diversas áreas de conhecimento. Posteriormente, tornou-se um instrumento que contribui para o ingresso desses alunos em universidades públicas brasileiras, o que facilitaria o acesso das classes menos privilegiadas ao Ensino Superior. 
Nesse sentido, o ENEM deixa de ser um instrumento de pesquisa e passa a ser uma estratégia de transformação da parcela de estudantes que futuramente ingressará no mercado de trabalho. É, ao mesmo tempo, uma política de enriquecimento do sistema educacional brasileiro, mas também uma tática de inserção do País no ranking dos países da América Latina, capazes de movimentar o mercado econômico e propiciar mais investimentos estrangeiros no Brasil, tornando-se, futuramente, um país cuja população apresentará uma formação escolar adequada aos propósitos econômicos mundiais, podendo então se consolidar como uma possível liderança na América Latina e ocupar um posto para a tomada de decisóes.

O ENEM é, portanto, uma das estratégias empreendidas pelo governo federal e, como instrumento de avaliação em larga escala, em território nacional, tem apresentado interferências na realidade do ensino nas escolas, embora ainda seja cercado por dificuldades de execução do processo.

Considerando os dados relativos ao desempenho de estudantes do EM, no que diz respeito à Leitura e à Produçăo Textual, pode-se considerar que os índices brasileiros de leitura e redação ainda estão distantes dos números almejados. Entretanto, percebe-se um leve aumento na qualidade dos resultados obtidos nos exames nacionais e internacionais, mas, podese ressaltar que novos projetos de ensino de língua portuguesa têm sido empreendidos por todo o país. Na seção seguinte, será analisado como o Estado de Goiás tem aplicado as diretrizes educacionais para o ensino de Língua Portuguesa e como as escolas têm incorporado essas diretrizes na prática escolar.

\section{Políticas linguísticas no Estado de Goiás: a implementação das diretrizes curriculares nacionais}

A maioria dos brasileiros desconhece que, no Brasil, não existe um currículo escolar mínimo em âmbito nacional; existem "diretrizes para o currículo", que apenas indicam orientaçóes e que muitas vezes não são discutidas nas escolas, nas reunióes de início do ano letivo. A tarefa de escolher os conteúdos, a metodologia, e qual perspectiva deve ser adotada, cabe, na maioria das vezes, à escola ou ao próprio professor.

A prova do ENEM, por exemplo, privilegia o raciocínio interpretativo e dispensa o simples acúmulo decorado de conteúdos. Entretanto, essa não é a forma de ensino na maioria das escolas do país, no que diz respeito ao 
ensino de Língua Portuguesa. Na escola, há uma profusão de particularidades em relação à forma como os professores ministram o conteúdo e que estão há vários anos trabalhando em educação, sem motivação ou sem condiçóes para se atualizar. Todas essas particularidades acabam influenciando diretamente o aluno que, ao final do Ensino Médio, náo desenvolve muitas capacidades apregoadas pela Lei de Diretrizes e Bases da Educação Nacional que determina, em seu Art. 36, $\$ 1$ \% o "domínio dos princípios científicos e tecnológicos que presidem a produçáo moderna; conhecimento das formas contemporâneas de linguagem, entre outros".

Nesse sentido, em um contexto mais restrito, a Secretaria de Educação do Estado de Goiás, a partir de 2010, vem implantando algumas políticas públicas em educação com a finalidade de melhorar os índices do IDEB no Estado. Enquanto, no Brasil, estudantes do $9^{\circ}$ ano do Ensino Fundamental atingiram nota igual ou superior ao que o MEC considera ideal, em Goiás, alunos de apenas quatro estabelecimentos públicos de ensino, em um universo de quase 1,1 mil, alcançaram a média esperada na Prova Brasil e no Censo Escolar, sendo unificados os dados de proficiência em Língua Portuguesa e Matemática, além dos dados de aprovação, reprovação e evasão escolar.

O Estado de Goiás apresenta IDEB do Ensino Fundamental superior a 4 (quatro) pontos, mas algumas escolas têm nota inferior a 1 (um). A média 6,0 (seis) pontos é a mesma considerada ideal pelos países ricos da Organização para a Cooperação e Desenvolvimento Econômico (OCDE) e deve ser universalizada em todo o ensino básico brasileiro até 2021. Para que isso aconteça, até lá, metas intermediárias foram estabelecidas e, mesmo o País avançando com relação a elas, ainda está distante do nível razoável.

No Quadro 4, há os resultados e as previsões de notas em relação aos alunos concluintes do Ensino Médio (3a Série) no Estado de Goiás:

Quadro 4. IDEB do Estado de Goiás

\begin{tabular}{|l|c|c|c|c|c|c|c|c|c|c|c|}
\hline Estado & \multicolumn{3}{|c|}{ IDEB Observado } & \multicolumn{10}{|c|}{ Metas Projetadas } \\
\hline Goiás & 2005 & 2007 & 2009 & 2007 & 2009 & 2011 & 2013 & 2015 & 2017 & 2019 & 2021 \\
\hline Nota & 2.9 & 2.8 & 3.1 & 2.9 & 3.0 & 3.2 & 3.4 & 3.8 & 4.2 & 4.4 & 4.7 \\
\hline
\end{tabular}

Com base em diversas pesquisas, o estado de Goiás percebeu um alto índice de evasão entre alunos do Ensino Médio e, em virtude desses índices, decidiu estabelecer, no ano de 2007, as bases de um programa com uma ressignificação do Ensino Médio no estado, que prevê o aumento da 
carga horária das aulas, a oferta de matérias optativas, a mudança para um sistema semestral, além da valorização dos temas transversais. Entretanto, após acaloradas discussóes, com a maioria do corpo escolar se posicionando contra e após mudanças políticas no Estado, o projeto náo foi mais discutido. Recentemente, no início de 2011, a Secretaria de Educação do Estado de Goiás, após recentes pesquisas sobre educação mostrarem que o desempenho dos estudantes goianos estava abaixo do esperado em Língua Portuguesa, resolveu estabelecer uma "Avaliação diagnóstica" nessa disciplina.

Seguindo a tendência mundial de avaliação em larga escala, as provas desse projeto têm a intenção de avaliar a capacidade de leitura e de solução de problemas, detectar pontualmente o déficit de ensino e aprendizagem. De acordo com a Secretaria de Educação do Estado de Goiás, a avaliação vai apontar o que precisa ser revisto nos conteúdos específicos e corrigir equívocos na aplicação dos conteúdos. A proposta da Secretaria de Educação ainda apresenta algumas inconsistências, evidenciando problemas relativos ao planejamento das avaliaçóes. Os resultados confirmam que os alunos da segunda fase do Ensino Fundamental são os que apresentam maiores dificuldades em Língua Portuguesa, com médias para estudantes de $9^{\circ}$ ano de 4,4 nessa disciplina.

Vale lembrar que as escolas têm à disposição diretrizes que orientam o ensino da Língua Portuguesa no Brasil, conforme os PCN, mas nem todas as escolas e todos os professores trabalham os conteúdos da mesma maneira. A realidade do ensino, no entanto, não condiz com a "matriz de referência" do ENEM, muito menos com o que é cobrado do aluno na avaliação diagnóstica da Secretaria Estadual de Educação de Goiás. Nem sempre fica evidente a conexão entre habilidades e conhecimentos que são exigidos do aluno na prova do ENEM. O conjunto dessas competências vai muito além de apenas preencher lacunas e saber termos gramaticais. Analisar sintaticamente um enunciado não se limita a identificar e rotular os termos da oração. Uma questão como "Transcreva todos os substantivos do texto, classificando-os”, retirada de um livro didático do Ensino Médio, não será igual àquelas que serão cobradas dos alunos nem no ENEM, nem na Avaliação Diagnóstica do Estado de Goiás, ou em qualquer outro sistema de avaliação em larga escala.

Uma questão descontextualizada como a apresentada acima, utilizada por várias escolas, de forma alguma é direciona pelos preceitos que norteiam as competências exigidas pelo ENEM, pelos PCN e pelas diretrizes exigidas 
pelo Estado de Goiás através da Avaliação Diagnóstica, o que indica que a reformulação do ensino de Língua Portuguesa deve também atingir as práticas de ensino, bem como os materiais didáticos fornecidos aos estudantes.

\section{Consideraçóes finais}

De uma maneira geral, ao se observar a história da educação brasileira, nota-se uma descontinuidade em relação às políticas públicas no Brasil. Seja a educação encarada como prioridade ou não para as políticas de governo no país, a ausência de políticas linguísticas adequadas de ensino de língua materna levou o Brasil a apresentar os índices atuais de desempenho educacional nos sistemas de avaliação como ENEM, PISA, Prova Brasil etc.

O direcionamento do olhar para as políticas de Ensino Médio, no Brasil, tem salientado algumas açóes semelhantes em todos os estados. Em Goiás, no Centro de Ensino e Pesquisa Aplicada à Educação, a discussão e implementação de um currículo diferenciado, construído a partir das necessidades e dos interesses apontados pelos alunos do Ensino Médio, possibilitou o estabelecimento de um Núcleo Básico de disciplinas e de outro Núcleo Diversificado de disciplinas optativas e condizentes com as áreas de conhecimento pleiteadas pelos alunos como áreas de atuação futura (DELGADO, 2005; FILETTI, 2010).

Essas açốes discutem e promovem a transformação das diretrizes curriculares, de propostas teórico-metodológicas, multidisciplinares ou interdisciplinares, assim como de programas destinados a alunos com dificuldades escolares, na tentativa de melhorar as condiçóes de aprendizagem paralelamente às aulas ordinárias. Outro ponto que merece destaque, nesse processo de transformação do currículo escolar, é novamente ressaltado: a necessidade de uma formaçáo continuada de professores e uma discussão séria acerca da avaliação nas escolas municipais, estaduais e federais.

Pensando em um planejamento que se estenda em um plano de açôes de médio e longo prazo, o Brasil poderá exibir melhores índices de desempenho escolar. $\mathrm{O}$ investimento econômico em Educação pressupóe açôes imediatas e resultados processuais que poderão ser muito satisfatórios se o tempo necessário for concedido e o foco não for desviado.

Não se trata somente de estabelecer metas e projetos de revisão de conteúdos para preparar os estudantes para obterem bons rendimentos nas avaliaçóes nacionais e internacionais. Trata-se, sobretudo, de possibilitar à geração atual de alunos e professores o reconhecimento do valor da edu- 
cação, das manifestações culturais e da língua, como integrantes da identidade de um povo. É necessário que a crítica feita aos desempenhos obtidos seja revertida para incrementar a qualidade do ensino em todos os níveis do sistema educacional. O planejamento das políticas públicas e linguísticas, ou de qualquer outra área do conhecimento, deve estar coeso, ser uma condição indispensável para a reflexão sobre as estratégias mais adequadas a cada contexto social, com a reflexão sobre as prioridades da educação e, especialmente, sobre o investimento na formação de professores-pesquisadores da Educação Básica, uma vez que eles são os mediadores dos valores sociolinguísticos da sociedade brasileira.

A valorização da educação como uma instância basilar da sociedade enfrentará oposições se o poder público tornar opaca a legislação e o cumprimento das leis e dos princípios previstos na LDB. Um estado democrático de fato deve promover e valorizar uma nação letrada, consciente de seu papel em sociedade, posto que isso já coloca uma naçáo em igualdade com qualquer outra.

Levar o Brasil a estar em igualdade com outras naçóes implica construir novas alternativas de organização curricular nas escolas de Educação Básica, mas, sobretudo, garantir que os recursos da União sejam direcionados para metas específicas e previstos pelas instâncias governamentais de educação. Nesse sentido, a formação humana constituirá a essência da organização socioeconômica da nação e propiciará maior satisfação a seus cidadãos.

\section{Referências}

BAKHTIN, Mikhail. Marxismo e filosofia da linguagem. São Paulo: Hucitec, 1997. $196 \mathrm{p}$.

BOURDIEU, Pierre. A economia das trocas simbólicas. São Paulo: Perspectiva, 2007. 337p.

BRASIL. MEC. INEP. Investimento em educação atinge meta de 5\% do PIB. Brasília, 2010. Disponível em: <http://www.sic.inep.gov.br/pt/component/ content/article/908-brasil-investimento-em-educacao-atinge-meta-de-5do-pib>. Acesso em: 19 out. 2011.

BRASIL. MEC. INEP. Lei de Diretrizes e Bases da Educação Nacional. 5. ed. Biblioteca digital da Câmara dos Deputados. Centro de Informação: Brasília, 2010. p. 7-58. Disponível em: <http://www.bd.camara.gov.br>. Acesso em: 10 out. 2010. 
BRASIL. MEC. INEP. Programa Internacional de Avaliação de Alunos. Brasília, 2009. Disponível em: <http://portal.inep.gov.br/internacionalnovo-pisa-resultados>. Acesso em: 10 out. 2010.

BRASIL. MEC. Orientaçōes Curriculares para o Ensino Médio. Linguagens, códigos e suas tecnologias. Brasília: Secretaria de Educação Básica, 2008. 239p.

BRASIL. MEC. Secretaria de Educação Básica. Programa Ensino Médio Inovador. Documento orientador. Brasília, SEB, set. 2009. 29p. Disponível em: <http://portal.mec.gov.br/dmdocuments/documento_orientador. pdf.>. Acesso em: 23 out. 2010.

DELGADO, Andréa Ferreira. A reforma curricular do ensino médio no CEPAE. Revista Solta a Voz, v. 16, n. 2. Goiânia, p. 109-124, 2005.

FILETTI, Elisandra. O ensino de língua portuguesa em Goiás: perspectivas para o Ensino Médio. In: Anais do IV Encontro Estadual de Didática e Prática de Ensino. Pontifícia Universidade Católica de Goiás, Goiânia, 2010. p. 1-11. GATTI, Bernadete A. Avaliação de sistemas educacionais no Brasil. Sísifo: Revista de Ciências da Educação, n. 9, maio/ago. p. 7-18, 2009.

GOIÁS. Secretaria da Educação do Estado De Goiás. Avaliação diagnóstica nas escolas estaduais de Goiás. Goiânia, 2011. Disponível em: <http://www. see.go.gov.br/imprensa/documentos /arquivos/2>. Acesso em: 29 out. 2011.

INEP. Disponível em: <http://www.inep.gov.br>. Acesso em: 10 out. 2010.

LYRA SILVA, Gene Maria Vieira. Dimensóes legais da política de financiamento educacional após a Constituição Federal de 1988. Revista Antitese-Marxismo e Cultura Socialista, n. 2. Goiânia, p. 61-76, 2006.

NEVES, Maria Helena de Moura. Que gramática estudar na escola? Norma e uso na Língua Portuguesa. São Paulo: Contexto, 2003. 174p.

NEVES, Maria Helena de Moura. Ensino de língua e vivência de linguagem. Temas em confronto. São Paulo: Contexto, 2010. 286 p.

Recebido em: 19 out. 2012

Aceito em: 30 nov. 2012 